\title{
TEATRO LIMINAL Y GÉNERO: SOBRE LOS PROCEDIMIENTOS ESCÉNICOS UTILIZADOS EN LAS PRÁCTICAS DRAG KING EN BUENOS AIRES
}

\author{
LIMINAL THEATER AND GENDER: THE SCENIC PROCEDURES \\ USED IN DRAG KING PRACTICES IN BUENOS AIRES
}

AgustinaTrupia

CONICET - IAE, FFyL, UBA

(agustinatrupia@gmail.com)

https://orcid.org/0000-0001-9450-8099

\begin{abstract}
(c)
DOI: https://doi.org/10.32621/acotaciones.2020.44.05

ISSN 2444-3948

Resumen: El artículo propone, como principal objetivo, estudiar las indagaciones artísticas en torno a las masculinidades femeninas. Para esto, se parte de la filosofía del teatro para analizar dos espacios escénicos diferentes en los que se dan estas búsquedas. Por un lado, se trabaja con la Carrera de reyes, espacio de competencias de Jrag kings en Buenos Aires, y con dos artistas transformistas en particular. Por otro lado, se analizarán los procedimientos de travestismo escénico en Petróleo, obra del grupo Piel de lava, estrenada en 2018. Se busca ampliar las nociones de tradicionales de teatro al incluir las prácticas artísticas de transformistas y también se revisa la presencia escénica de las mujeres que exploran las masculinidades. Asimismo, se plantea dimensionar las consecuencias que tienen estas prácticas en la historia del teatro y en las identidades de género de les espectadores.
\end{abstract}


Palabras Clave: Jrag king, masculinidades, performance, Jrag queen, género.

Abstract: In theatrical performances, the building of aesthetic belief and empathy on spectators is a whole. This matter has been looked into by theatrology and it has been, since classical rhetoric, a relevant technical preoccupation linked to perceptual capture, spectator seduction and affective impact of scenic discourse. In this article, given the preeminence in Argentina of studies based on semiotic perspectives, from the point of view of the researcher-artist role, links between rhetoric and theatre are formulated concerning the procedures of verisimilitude configuration that form a scene/spectator relationship paradigm, pertinent to the theatrical acting and staging question.

Key Words: drag king, masculinities, performance, drag queen, gender.

Sumario: 1 Ensayando masculinidades: hombres trabajando. 2. Herramientas para nuestro abordaje: es obligatorio el uso del casco. 3. Reyes para construir: pintura fresca. 4. Peones trabajando: precaución. 5. Algunos arribos: zona en construcción. 6. Obras citadas. 7. Notas

Copyright: (C) 2020. Este es un artículo abierto distribuido bajo los términos de una licencia de uso y distribución Creative Commons 4.0 Internacional (CC BY 4.0)

Agustina Trupia se encuentra haciendo el doctorado en Historia y Teoría de las Artes en la Universidad de Buenos Aires y es becaria interna doctoral del CONICET. Se recibió con diploma de honor de Licenciada en Artes Combinadas y Profesora de Educación Media y Superior en Artes Combinadas en la Facultad de Filosofía y Letras, Universidad de Buenos Aires. Es adscripta a la cátedra de Historia del Cine Latinoamericano y Argentino de la misma casa de estudios y trabaja como docente en instituciones de nivel medio. Es jurado de los Premios Teatro del Mundo otorgados por el Centro Cultural Rector Ricardo Rojas y es investigadora del Instituto de Artes del Espectáculo «Dr. Raúl H. Castagnino» de la UBA. 


\section{ENSAYANDO MASCULINIDADES: HOMBRES TRABAJANDO}

Desde comienzos de este nuevo siglo, en la Ciudad Autónoma de Buenos Aires, capital de Argentina, se encuentran diversos espacios en los que se desarrollan las prácticas artísticas de transformistas. Estas prácticas poseen una extensa trayectoria en la escena teatral. Como parte de sus posibles antecedentes, encontramos algunas prácticas que, aunque fueron diferentes de lo que comprendemos en la actualidad como transformismo, pueden ser consideradas como parte de su historia. Estas redes vinculares de prácticas deben ser aún tejidas, pero podemos por el momento mencionar algunos de los nodos que la componen.

En lo que respecta a la historia del teatro, la presencia del travestismo escénico, surgida como la consecuencia a la prohibición de que las mujeres actuaran sobre los escenarios, podría ser evaluada como un antecedente de las prácticas transformistas actuales. Trastoy y Zayas de Lima (2006) mencionan el caso, en el teatro japonés del siglo XVII, de la figura del onnogata, encargado de realizar los personajes femeninos en el kabuki. Asimismo, podría mencionarse el teatro isabelino en Inglaterra y la realización de los diversos personajes femeninos por parte de actores varones como otra posibilidad de pensar conexiones con las prácticas transformistas actuales.

Sin embargo, estos ejemplos presentan al menos dos cuestiones relevantes para detenernos. Por un lado, distan de la concepción de transformismo que tenemos en la actualidad en Buenos Aires, dado que, como veremos más adelante, estas prácticas vinculadas estrechamente a la espectacularidad escénica trascienden la instancia de mostración frente a un público y adquieren una dimensión política que complejiza las identidades de quienes las realizan. Asimismo, veremos que en la actualidad encontramos una variedad de prácticas transformistas que no se sitúan desde el binarismo de géneros, es decir, no son artistas varones que personifican a una mujer, sino que realizan otro tipo de construcciones performáticas.

Por otro lado, los casos históricos mencionados se centran en la interpretación de personajes femeninos por parte de varones como resultado de la restricción patriarcal de las mujeres en la esfera pública artística. Hallamos que, en la actualidad, podría haber vestigios de esta postura, aun cuando las mujeres podamos participar en escena. Con esto deseamos evidenciar que la escena transformista actual en Buenos Aires tiene 
como principales exponentes las prácticas drag queen. Esto hace referencia a las exploraciones en torno con las feminidades por parte de varones cis como transgénero (aunque en menor medida también, por parte de mujeres o personas no binarias). Sin embargo, en la escena drag queen porteña actual algunos de los estilos que se encuentran complejizan esta definición. Muches ${ }^{1}$ artistas componen personajes que utilizan accesorios y vestuarios culturalmente asociados a las identidades femeninas, pero que producen puestas en escena de corporalidades fantasiosas que escapan de cualquier clasificación binaria.

Desde las revisiones hechas por la academia, en reiteradas investigaciones, se han estudiado los trabajos de varones que interpretan personajes femeninos. Encontramos estudios que han realizado aportes sumamente relevantes en este sentido como el de Mina Bevacqua (2016) sobre las prácticas de Batato Barea y el de Ezequiel Lozano (2015), quien aborda el travestismo escénico realizado en la década del sesenta. Sin embargo, consideramos que hay una zona de vacancia en lo que respecta al estudio de las prácticas locales Jrag king, es decir, aquellas que indagan e investigan los modos en que pueden representarse las masculinidades a partir del uso de elementos que culturalmente son asociados con ellas. Estas prácticas son realizadas tanto por mujeres cis y transgénero como por personas no binarias.

La investigadora Alba Pons Rabasa (2018) propone una definición de la práctica Jrag king como «una metodología feminista de investigación encarnada que nos permite reflexionar en torno a la identidad de género en tanto experiencia, pero también en tanto categoría teórica y política» (pág. 56). Comparto su modo de comprender a estas prácticas y se verá, a lo largo del artículo, el entrelazamiento entre los cuestionamientos a las identidades de género instauradas como únicas posibilidades y las indagaciones políticas tanto de quienes se montan como de quienes participamos como espectadores.

Resulta pertinente, en este punto, mencionar el apartado sobre transformismo que elabora Sosa Cordero (1978) en su libro sobre las varietés de Buenos Aires a comienzos del siglo XX. En este, el término «transformista» está asociado a la realización por parte de una actriz o actor de diversos personajes en un mismo espectáculo. Esta noción se hallaría más cercana a la idea actual de la labor de imitación. Más allá de la escritura del autor, que evidencia una concepción binaria y, en muchos casos, incluso retoma secciones de periódicos de la época sin señalar 
que contienen juicios despectivos hacia las disidencias sexuales, me interesa rescatar la figura de Fátima Miris, quien actuó en Argentina en 1913. Esta artista italiana es mencionada por Sosa Cordero como una figura destacada dentro del transformismo, luego de Leopoldo Frégoli. Se rescata como principales características de su labor su capacidad para interpretar en un mismo espectáculo a decenas de personajes, su velocidad inusitada para cambiar de uno a otro $y$, por sobre todo, su capacidad para realizar personajes masculinos. «De su voz atiplada lograba una gama de matices realmente inaudita, que descendía en ocasiones a tonalidades baritonales» (Sosa Cordero, 1978, pág. 129). De este modo, más allá de las diferencias, Miris es una de las artistas que puede ponerse en relación con las prácticas drag king actuales.

Asimismo, al pensar las relaciones entre el transformismo y el travestismo en la escena de la década del sesenta en Buenos Aires, Lozano (2015) retoma un trabajo de Jorge Salessi de 1991. En este se plantea que «en el prostíbulo del tango vemos la 'inversión' de mujeres 'masculinas'» (Lozano, 2015, pág. 46). Esto da cuenta de una serie de mujeres que adoptan para la interpretación, en el ámbito de la canción popular, marcas de género que son culturalmente asociadas con la masculinidad.

Más allá de estos ámbitos artísticos aquí mencionados, es importante señalar que los espacios del carnaval como los corsos y el circo también resultaron propicios para la aparición de personajes masculinos realizados por mujeres. Me interesa señalar esto, dado que algunos de los espacios con los que trabajaremos particularmente en este artículo corresponden a espacios propios de la liminalidad teatral.

Volviendo al momento actual, en la escena porteña hay una importante presencia de prácticas transformistas. Cuando hablamos de transformismo nos referimos a las performances que realizan artistas en las que componen personajes con un determinado nombre el cual es sostenido a lo largo del tiempo, aunque el vestuario y maquillaje varíe. Es decir, se constituye una identidad y en cada presentación la utilización creativa y disruptiva del maquillaje, peluca y vestuario se modifica. Puede ser productivo recordar la propuesta de Esther Newton (1972) quien describe la práctica drag como discontinuidades entre apariencia y realidad, pero que no se la piensa como disfunción, sino que esta incongruencia es el lugar de la creatividad del género sobre la que se sostiene.

Hay espacios festivos en Buenos Aires que son autogestionados por artistas Jrag queen como por ejemplo Trabestia Drag Club. Este es un 
espacio nocturno en el que se lleva a cabo una fiesta con la particularidad de contar con números artísticos que son realizados por artistas Jrag. Hay otros espacios como como La Drag Fiesta o Namunkurá que, junto con las competencias que se realizan en las fiestas Turbo, constituyen lugarez centrales para la escena de escena liminal Jrag.

Les artistas Jrag queen que se encuentran en estos espacios conforman diferentes estilos. Son tanto varones cis y transgénero como mujeres cis o trans y personas no binarias quienes se draguean. Es decir, esta práctica consta de la exploración de las posibilidades que posee el propio cuerpo (e identidad) a partir de los elementos que son culturalmente asociados a las feminidades como los tacos, maquillaje, vestidos, y tiene como resultado la construcción de un personaje que se muestra frente a espectadores. Hay diversos estilos de Jrag queens, cuya mención no son objeto de este artículo, pero de modo resumido podríamos mencionar un estilo de transformismo ligado a la representación de personajes femeninos (dentro de los cuales se hallan diversos tipos de feminidad); y otro tipo de construcción vinculadas a lo fantasioso y lejano de las representaciones humanas. Esta última categoría se relaciona con la constitución de identidades que escapan a la posibilidad de ser nombradas: no tienen un objeto de representación cercano a la realidad, sino que exploran otros universos de referencia.

De manera aún más reciente, aparecieron en Buenos Aires espacios propios para el desarrollo de las prácticas Jrag king y uno de estos será abordado en este artículo. La intención es estudiar los modos en que se aborda la masculinidad en las prácticas artísticas liminales de quienes se montan al modo drag king. Para esto, en primer lugar, se analizará la Carrera de reyes, un espacio de indagación en torno a la masculinidad por parte de identidades vinculadas a la feminidad o no binarias. Desde el 2018, se vienen llevando a cabo competencias bajo distintas categorías. En ellas, para participar se debe realizar una inscripción previa en la que se brinde un nombre $\partial \mathrm{rag}$. Estas competencias tienen lugar en el barrio porteño de Almagro en Feliza, un espacio cultural LGBTIQ+ de gran relevancia por la programación de actividades que propone y su importancia en tanto lugar cuidado para quienes asistimos. Se incluirá el estudio de dos artistas drag que allí se presentan para pensar las potencialidades de estas prácticas, sus constituciones corporales y los modos en que abordan las identidades de género. 
En segundo lugar, se trabajará con la obra de teatro Petróleo del grupo Piel de lava, estrenada en 2018, en la cual cuatro actrices mujeres llevan adelante cuatro personajes masculinos. Por el momento, podemos adelantar que en este acontecimiento teatral no hay una práctica $\partial r a g$ king, pero me interesa el modo en que se piensa y se lleva a cabo la masculinidad al construir los personajes de trabajadores de la industria del petróleo. Se buscará pensar en relación las prácticas de estas masculinidades con las que se presentan en las manifestaciones drag de Carrera de reyes.

En su estudio en torno a la masculinidad femenina, Jack Halberstam (2008) piensa los modos en que las identidades femeninas encarnan la masculinidad. Lo que propone es que la masculinidad no es una práctica exclusiva de los varones, en particular de los varones de clase media blancos heterosexuales, sino que también lo es del resto de los sujetos. Uno de los puntos más interesantes de su estudio en torno a distintas prácticas Jrag king con las que trabaja, es que en ellas se «muestra la estructura de la masculinidad dominante al hacerla teatral» (pág. 266). Es decir, en la sociedad hay formas de masculinidad que se postulan a sí mismas como auténticas, haciendo parecer que las demás formas son derivados de ellas. Halberstam plantea incluso que una de las grandes conquistas de las prácticas Jrag king es evidenciar que la masculinidad también es visible y teatral. En particular hace referencia al hombre blanco heterosexual, dado que las otras masculinidades, como las de personas de clases bajas u homosexuales, por ejemplo, son frecuentemente teatralizadas en relación con la masculinidad dominante. Estas prácticas dejan en evidencia que el postulado de la naturaleza no performativa de la masculinidad dominante no es tal al desidentificarla de «lo natural» $\mathrm{y}$ volverla imitable, tal como postula Halberstam (2008, pág. 261).

Este autor propone un término que será central para analizar las performances que se llevan a cabo en la Carrera de reyes de Buenos Aires. Introduce el término en inglés kinging para denominar el humor asociado a la masculinidad y como modo de diferenciar las prácticas de las mujeres, lesbianas y trans con las prácticas de los varones gay y el camp. Según plantea Halberstam, lo cómico de la feminidad en las prácticas Jrag queen está dado a partir de la estética gay, pero no habría una «imagen comercial de la masculinidad que reconociera estar utilizando la masculinidad lesbiana» (pág. 267) a modo de equivalencia. Me parece 
en este punto necesario recordar que, en la escena transformista de Buenos Aires, las indagaciones por parte de artistas Jrag queen no pueden ser reducidas a la representación de la feminidad, dado que, hay múltiples estilos que remiten a otras referencias.

Resulta interesante lo que plantea Judith Butler (2000) cuando postula que no hay un género original que el travestismo ( $y$ aquí agrego: el transformismo) imita, sino que «el género es un tipo de imitación que no tiene un original, que produce la noción de original como efecto y consecuencia de la imitación misma» (pág. 99). La autora plantea a la heterosexualidad como una repetición compulsiva que solo logra producir un efecto de su propia originalidad. Sobre la construcción de la homosexualidad como copia, se funda la idea de heterosexualidad como original. La idea planteada por Butler (2000) de que «la copia produce e invierte los términos de prioridad y derivación» (pág. 100). Podríamos pensar también que las prácticas Jrag king, con sus efectos paródicos, exponen a la heterosexualidad como una imitación incesante de su idealización naturalizada. Butler insiste en que la necesidad de la heterosexualidad de la repetición pone en evidencia su riesgo continuo y es este fracaso de la heterosexualidad naturalizada lo que es utilizado en prácticas $\partial r a g$ a modo de subversión de las normas de género.

2. Herramientas Para nUESTro abordaJE: ES OBligatorio EL USO DEL CASCO

Antes de avanzar con los casos particulares que se analizarán en este artículo, deseo retomar a Blas Radi (2019), quien propone una epistemología transgénero que ponga en evidencia «las tramas de relaciones desiguales en la producción de conocimiento» (pág. 31). El autor menciona prácticas como la objetificación epistémica, el extractivismo académico, la constricción de unx «otrx» y el uso instrumental, las cuales suelen estar presentes en investigaciones que trabajan desde el cisexismo. Una de las preocupaciones principales de este trabajo es no replicar estos modelos totalizadores y colonialistas de pensamiento. Por el momento, encuentro que mi deseo de trabajar con las prácticas de artistas transformistas se vincula directamente a aquello que se ha movilizado en mí desde las primeras veces, anteriores al comienzo de mi investigación formal, en que asistí a las fiestas y espacios autogestionados 
por artistas drag. Recordar la contención que me proporcionaron estos espacios festivos y la fascinación que me produjeron y produce el arte drag es central. Mi conexión con las prácticas que estudio no tienen un origen académico y objetual, sino que está ligado a lo emocional, celebratorio e identitario.

Asimismo, encuentro en las ideas de Donna Haraway, quien también es retomada por Blas Radi, una posible respuesta. «La visión situada, encarnada y parcial ofrece una perspectiva que no promete ni aspira a la transcendencia, ni a abarcarlo todo desde ningún lugar, sino que asume la responsabilidad de explicitar sus propias coordenadas» (Blas Radi, 2019, pág. 37). Asimismo, Haraway (1995) plantea una escritura feminista del cuerpo que acentúe la visión como modo de enfrentar los poderes de las ciencias y las tecnologías modernos que transformaron los debates sobre la objetividad (pág. 326). Comparto con la autora su interés por revelar a la objetividad como una falsa visión que promete la trascendencia de los límites «para dedicarse a una encarnación particular y específica» (pág. 326). La objetividad feminista, que me propongo a partir de Haraway, se trata de una localización limitada y del conocimiento situado. Entre la objetividad, postulada como la trascendencia de los propios límites y totalización de la ideología, y el relativismo, «una manera de no estar en ningún sitio mientras se pretende estar en todas partes» (Haraway, 1995, pág. 329), se halla la epistemología de las perspectivas parciales.

Por lo tanto, en este artículo intento abordar las prácticas drag junto con los procedimientos travestismo escénico intentando no ofrecer categorías que busquen clausurar el potencial disruptivo de dichas manifestaciones. Intento nombrarlas de manera precaria, sabiendo que se encuentran en un movimiento constante de desidentificación. La precariedad en este caso parece ser la base de la creatividad y del movimiento insurgente que llevan consigo mismas. Desde mi lugar que es, por ahora, el de quien disfruta los mundos que se despliegan frente a las prácticas $\partial r a g$, me acerco a pensarlas para, en definitiva, pensarme a mí misma y que tal vez pueda resonar en quienes lean estas páginas.

Para el abordaje del corpus seleccionado, trabajo entonces con las propuestas de Radi y Haraway en conjunto con los postulados de la filosofía del teatro. Dentro de la teatrología argentina, desde hace varios años, Jorge Dubatti viene desarrollando la filosofía del teatro como modo de preguntarse por la ontología y la praxis teatral en un contexto 
definido. Desde allí, se piensa al teatro como acontecimiento, entendiéndolo de manera más amplia que como lo ha hecho la semiótica del teatro al pensarlo como conjunto de prácticas discursivas. La definición pragmática del teatro que postula Dubatti (2010) es que «es la fundación de una peculiar zona de experiencia y subjetividad en la que intervienen convivio-poíesid-expectación» (pág. 33). Si tomamos esta definición, podemos pensar a las prácticas de artistas drag que participan de los eventos como Carrera de reyes como un acontecimiento teatral. En esos espacios, hay reunión de cuerpos presentes: performers, técniques y espectadores se encuentran en un espacio y tiempo determinado. De hecho, es esta reunión de cuerpos, este encuentro lo que le da un carácter particular a estos espacios que se erigen como lugares que favorecen un sentimiento de comunidad y de contención para las identidades disidentes que allí asistimos.

Una parte de quienes asisten al convivio produce poíesis con su cuerpo a partir de acciones físicas y otro sector la expecta. Dubatti (2010, pág. 37 ) propone que el ente poético propone una zona posible de teatralidad, en tanto marca un salto ontológico. Este se da, en las prácticas artísticas $\partial \mathrm{rag}$, por medio de un proceso de resubjetivación e instalación de una entidad metafórica. Al montarse, quienes hacen $\partial \mathrm{rag}$, instalan una corporalidad autónoma diferente a la cotidiana que se compone por medio de elementos de vestuario, maquillaje y se acompaña por la voz y propuestas escénicas. A partir de estas producciones se inaugura una distancia ontológica que, en el caso de estas prácticas, se fusiona con el mundo cotidiano. Esto sucede cuando los nombres Jrag son utilizados por les mismes artistas por fuera de los momentos artísticos como modo de autodenominarse o cuando les performers se entremezclan con les espectadores en los espacios de encuentro una vez que están montades.

Es por estas características particulares que les espectadores que participamos del acontecimiento somos invitades a intervenir de manera activa: se nos pide que aplaudamos, gritemos, cantemos y bailemos. Somos incorporades por el acontecimiento poéticos por medio de estos mecanismos de participación. Son les performers quienes organizan la mirada de les espectadores, pero también puede suceder el recorrido a la inversa. Es decir, que quienes asistimos a estos eventos lo hagamos montades produciendo una organización de la mirada de les otres.

Por lo aquí descriptivo es que podemos considerar a las manifestaciones artísticas de Jrag kingo que participan en Carrera de reyes como 
acontecimientos propios del teatro liminal, concepto propuesto por Jorge Dubatti y que amplía los alcances de lo teatral. Por medio de la observación participante y la filosofía del teatro es que nos acercamos a las performances como también a la obra creada por el grupo de mujeres Piel de lava.

\section{REYES PARA CONSTRUIR: PINTURA FRESCA}

Carrera de reyes es un concurso de Jrag kings que se organiza desde fines de 2018 en Feliza, un centro cultural importante dentro de la comunidad LGBTIQ+ de la Ciudad Autónoma de Buenos Aires. El anfitrión y fundador del evento es el Jrag king Armando A. Bruno. Los eventos que se realizan allí son difundidos por las redes sociales. Las cuentas de Instagram de quienes los organizan como la del perfil del evento y de quienes participan son los canales de comunicación que difunden la información sobre el horario, lugar y las consignas de cada encuentro. También es por este medio que se comparten las fotos y videos del evento realizado para otorgarle una mayor visibilidad. De este modo, se puede acceder a los textos que producen quienes organizan el espacio y se hace explícita la intención política de erigirse en contra del patriarcado y a favor del transfeminismo.

Asimismo, por medio de las redes sociales se invita a quienes quieran participar de la competencia a enviar el nombre $\partial r a g$, los pronombres personales con los que desean ser presentades, una descripción de aquello que se hará sobre el escenario y la música o audio con el que se vaya a realizar la performance. La Carrera de reyes presenta la posibilidad de que quien quiera subirse al escenario pueda hacerlo. De esta forma, se genera un espacio autogestionado y comunitario, que invita en cada evento a que más personas se animen a participar.

Hay consignas que engloban cada evento: se han propuesto los personajes de telenovelas como tema de la pasarela realness, es decir, la composición de personajes que se asimilen a una referencia. En esta competencia, gana quien puede componer un personaje con mayor verosimilitud. Otras consignas para la fantasía, es decir, la referencia que guíe la composición de la estética y personajes, han sido temáticas como la pascua, el invierno, la boda, lo pos solar entre otras. 
Los encuentros constan de una presentación sobre el escenario que realiza cada artista Jrag en la cual puede hacer un número de fonomímica con música o con poemas que se escuchen de fondo mientras se actúa o baila. Les ganadores son elegides en base al aplauso de les espectadores y a la evaluación de un jurado que se compone de otres artistas Jrag y referentes de la comunidad. En estos encuentros, se otorgan premios para quienes obtengan el primer y segundo puesto. Los premios pueden ser tragos del lugar donde se hace el evento, alguna prenda de ropa de un emprendimiento independiente o dinero en efectivo. A quien gana se le otorga una corona.

El encuentro suele comenzar alrededor de las diez de la noche. Les espectadores nos encontramos en la pista de baile del centro cultural Feliza frente a un pequeño escenario. En las competencias con jurado, éste se encuentra debajo del escenario de frente y ubicado alrededor de una pequeña mesa. Les espectadores podemos comprarnos bebidas en la barra del lugar y el diseño expectatorial que se propone implica el baile, aliento a les participantes y aplausos para emitir nuestros votos.

Esta modalidad de la competencia remite a la tradición con la que trabaja Halberstam de clubes queer en los que ha habido presentaciones

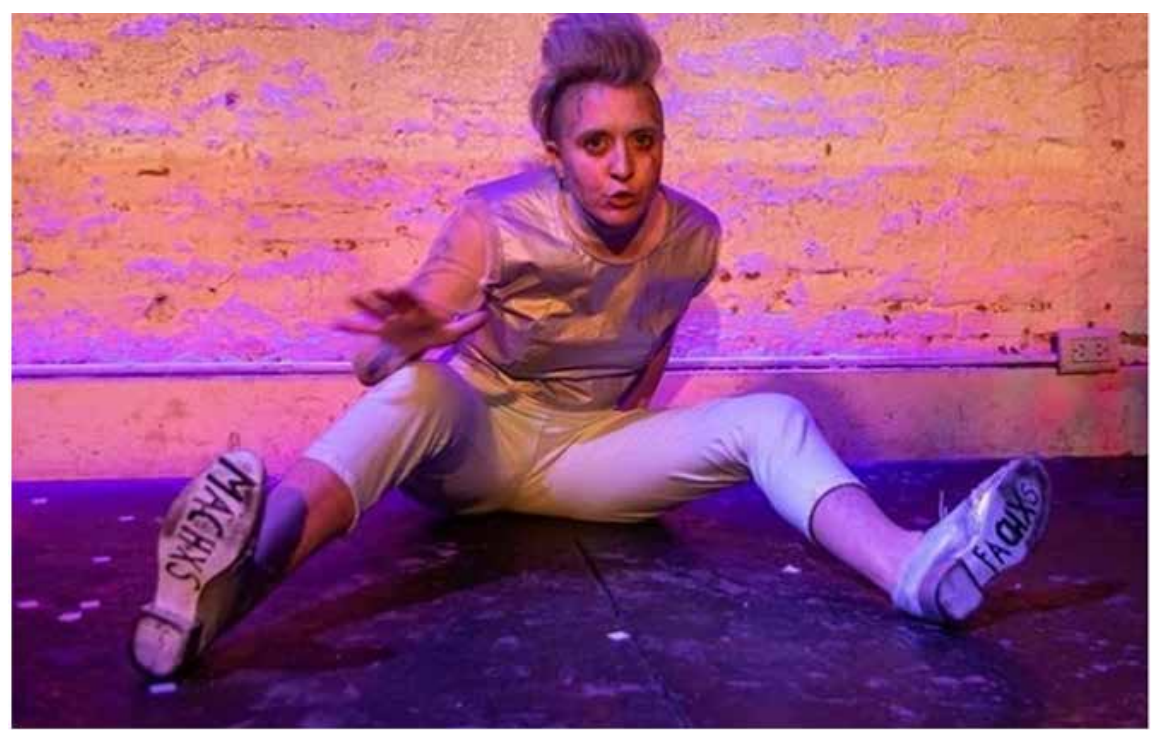

Rey a Ruedas, participante Jrag king, en Carrera de reyes en 2019.

Fotografía de Juli Ortiz@newtonxmetro 
y competencias de Jrag kings desde la década de 1990 en Estados Unidos. A su vez, estos espacios pueden pensarse en relación con las competencias de artistas Jrag queen que pueden observarse, por ejemplo, en la película estadounidense Paris is Burning (Jennie Livingston, 1990) y que también tienen presencia en ciertos espacios en Buenos Aires como las competencias de las fiestas Turbo.

Rey a Ruedas es uno de les artistas drag que participó y ganó en Carrera de reyes. En una de sus presentaciones, se subió al escenario con un vestuario plateado y blanco. Lució pantalones blancos hasta por debajo de la rodilla junto con una remera de mangas largas del mismo color y con una especie de chaleco entero de color plateado con unas importantes hombreras con unos pequeños dispositivos que despedían humo. Sus zapatos bajos y elegantes llevaban cordones en los mismos colores antes mencionados y en las suelas se podía leer «machxs fachxs». Usó el pelo corto con un rapado en los costados a modo de cresta y teñido de un color gris. En su rostro, tenía marcadas algunas venas de color azul: era la fantasía de invierno. El número de fonomímica que hizo sobre el escenario estaba vinculado a un texto con música que decía: «los pronombres primero se preguntan y después se respetan». Aquí nuevamente se ve la vinculación entre las performances y un posicionamiento político. Esto genera una posibilidad de identificación para quienes lo realizan: la misma práctica $\partial r a g$ se convierte en un vehículo de expresión artística y política. Asimismo, es un lugar de contención desde la expresión identitaria para quienes asistimos aun debajo del escenario.

A partir de las competencias de Jrag king a las que ha asistido en Estados Unidos, Halberstam (2008) propone una taxonomía de masculinidades femeninas para poder pensar las actuaciones de género. En el caso de Rey a Ruedas, se puede postular que la indagación de su masculinidad femenina está ligada a la masculinidad desnaturalizada. Es decir, se parte de una búsqueda mimética con la imagen más hegemónica del varón heterosexual, pero se realiza una apropiación con funciones críticas y se realiza así la personificación de una masculinidad alternativa. No hay en sus actuaciones una representación que resulte agraviante hacia los varones, sino que se centra en la exploración de la propia masculinidad y se combina con la creatividad propia del performer quien elabora su vestuario siguiendo las consignas otorgadas. 
Halberstam (2008) sugiere que:

el Jrag king demuestra, por medio de su propia masculinidad y por medio de la puesta en escena de la masculinidad, que no existe ningún vínculo esencial entre la misoginia y la masculinidad; más bien la masculinidad parece ligada estructuralmente a la misoginia en el contexto del patriarcado y del privilegio de los hombres (pág. 282).

Esta idea que plantea el autor, y que la escena drag local también introduce, es particularmente relevante en la actualidad al interior de los debates transfeministas. Entre las diversas discusiones que son presentadas, una ronda en torno a los modos en que pueden los varones construir y repensar sus propias masculinidades. Podemos comprender que es el sistema patriarcal cisexista y heteronormativo el que produce las violencias que sufren los cuerpos. Incluso podemos pensar que esta violencia se replica en el cuerpo de los varones mismos al ser sometidos a modos de socialización violentos, ubicando a la masculinidad y a su exploración en otro lugar.

Cuando en la Carrera de reyes se propuso como consigna la realización de galanes de telenovelas, se aclaró por medio de las redes sociales de la organización que se invitaba a pensar personajes que se alejaran de los estereotipos del macho misógino. Con esto quiero decir que hay una búsqueda para encarnar modos alternativos de masculinidades que no repliquen las violencias que sufrimos de manera sistemática todas aquellas identidades que no somos la de los varones cisgénero heterosexuales.

Es importante mencionar que este espacio, como los talleres de $\partial \mathrm{rag}$ king que comenzaron a dictarse en el último tiempo, son espacios jóvenes. En ellos se están ensayando modos de masculinidades y, en muchos casos, son personas que están comenzando a trabajar sobre el escenario. Pareciera ser una primera etapa de búsqueda de lugares de pertenencia $y$ de ofrecer una escena transformista alternativa a la que exploran artistas drag queen o a quienes ensayan modos más cercanos a las feminidades.

Pons Rabasa (2018), al reflexionar sobre su asistencia a talleres $\partial \mathrm{rag}$ king, los valora en tanto aquellos modos de performar masculinidades plurales permite generar «un espacio inédito de reflexión sobre la autenticidad de nuestras feminidades supuestamente originales y naturales» (pág. 71). Con lo cual esto produce un gesto cuestionador que va en la 
dirección de lo planteado por Halberstam, y retomado aquí, sobre el cuestionamiento a la masculinidad como grado cero, pero agrega que la propia identidad (aun si no es masculina) también es develada como una construcción social.

En el caso de Armando A. Bruno, quien gestiona el espacio de Carrera de reyes, luce el pelo corto, suele tener zapatos bajos con cordones (como los que se usarían con un traje), camisas arremangadas y cerradas hasta el último botón. Asimismo, lleva sombreros junto con tiradores o moños. Se maneja con una gestualidad medida, con las caderas abiertas y de manera aplomada. Lleva unos bigotes angostos y un poco más de vello en su mentón, acompañado por el maquillaje que agranda sus cejas oscuras y le da cierto marco de dureza a su expresión.

En su estilo de masculinidad podrían resonar las palabras de Halberstam cuando habla del mimetismo de hombre como cuando «el Jrag king adopta una masculinidad de hombre claramente identificable e intenta reproducirla» (pág. 277). Es interesante el modo en que esta construcción del personaje resuena en su nombre elegido: la cuestión de armarse también se ve amplificada por los talleres sobre drag king que ha brindado como por el espacio de las Carrera de reyes que generó como lugar para otres que quieran indagar en sus propias posibilidades corporales y de género.

Para una boda que se celebró entre Queer Borg y Vvinito, dos referentes de la escena transformista, en el marco de la Carrera de reyes en Feliza, Armando A. Bruno compuso el personaje de un pastor evangélico que les casaba en la performance. De este modo utilizó un traje de color negro, con una corbata color mostaza, junto con una cruz y biblia. También mostró su rostro maquillado con bigotes y anteojos. Este mimetismo de hombre posee, en el contexto de la performance sobre una boda en un centro cultural pensado para las disidencias de género, un uso irónico y crítico hacia la religión misma. De este modo, y siguiendo lo propuesto por Pons Rabasa, la práctica del dragueo desestabiliza al sujeto y desarma la coherencia que se pretende entre cuerpo, género y deseo. Y podemos agregar aún más: esta problematización que se abre a partir de un comportamiento momentáneo en una performance posibilita que se generen cambios conscientes en la performance cotidiana de quienes asistimos como espectadores. 


\section{Peones trabajando: Precaución}

Los universos de representación y significación que se despliegan cuando las mujeres cisgénero como transgénero o personas no binarias indagan su propia masculinidad son múltiples. En el caso de les artistas $\partial$ rag se han descrito dos casos en particular en el marco de las competencias que se realizan. En este sentido, es interesante trabajar con una obra de teatro estrenada en 2018 en Buenos Aires. Petróleo fue presentada por primera vez en el Teatro Sarmiento, parte del circuito de teatros oficiales de la ciudad, por el grupo de actrices, directoras y dramaturgas llamado Piel de lava. El grupo está compuesto por Elisa Carricajo, Valeria Correa, Pilar Gamboa y Laura Paredes, y desde hace diecisiete años se encuentra en actividad. De hecho, antes del estreno de aquella pieza, se había realizado en el mismo teatro una retrospectiva de su obra en el marco de un programa organizado por Vivi Tellas llamado Artistas en Residencia. Sus anteriores obras teatrales habían sido Colores verdaderos (2003), Neblina (2009), Tren (2009) у Museo (2014). En 2018 la película en la que participan las cuatro actrices, La flor de Mariano Llinás, recibió el premio a la mejor película en la competencia internacional en el BAFICI (el festival de cine independiente de Buenos Aires).

Petróleo cuenta con la codirección de Laura Fernández. La obra continuó su temporada en el 2019 en el Teatro San Martín, también parte del circuito de teatro oficial, y en el 2020 pasó al teatro Metropolitan Sura, parte del circuito comercial. En la obra, las cuatro actrices encarnan los personajes de cuatro varones que son trabajadores en de un pozo petrolífero en la Patagonia. El Formo, el Monto y el Carli, los nombres de los personajes, se encuentran compartiendo sus días de trabajo alejados de la sociedad y atendiendo la productividad de un pozo de petróleo que parece estar vacío. La llegada de El Palla modifica la dinámica del grupo en tanto se cuestionan las condiciones laborales bajo las que están sometidos como también las posibilidades en tanto vestimenta y sensibilidad que tienen permitidas por ser varones.

En una entrevista realizada al grupo en 2018 por María Daniela Yaccar para el periódico argentino Página 12, las actrices relatan que comenzaron el proceso creativo con la intención de «hacer de hombres». Como lo describe Valeria Correa: «primero apareció la idea del hombre. Después de qué hombre. Un hombre trabajando. ¿De qué trabajo? De uno que sea exclusivamente para hombres». Esto explica el entorno en 
el que se sitúan los personajes. El pozo petrolífero aparece como un espacio alejado de la sociedad y con condiciones laborales irregulares. El sometimiento de estos cuerpos y las responsabilidades desmedidas con las que cargan si el pozo deja de trabajar (esto se ve claramente cuando se corta la luz en un momento) son puestos en primer lugar.

Podríamos sugerir que no son prácticas drag king, sino que sería más conveniente hablar del procedimiento de travestismo escénico. No serían prácticas Jrag, dado que, hasta el momento, los personajes que se compusieron se circunscriben a una obra de teatro determinada. Incluso su misma creación fue realizada para aquella obra. Las personas que se Jraguean entienden, en su mayoría, a esta práctica como parte de su identidad de género aun cuando no están montadas. Lo Jrag trasciende el momento espectacular y la construcción se haya continuamente en proceso. Hay un modo de comprender la propia corporalidad como $\partial \mathrm{rag}$. Incluso les artistas mencionades antes se autodenominan con sus nombres $\partial r a g$ por fuera de las instancias de actuación ${ }^{2}$.

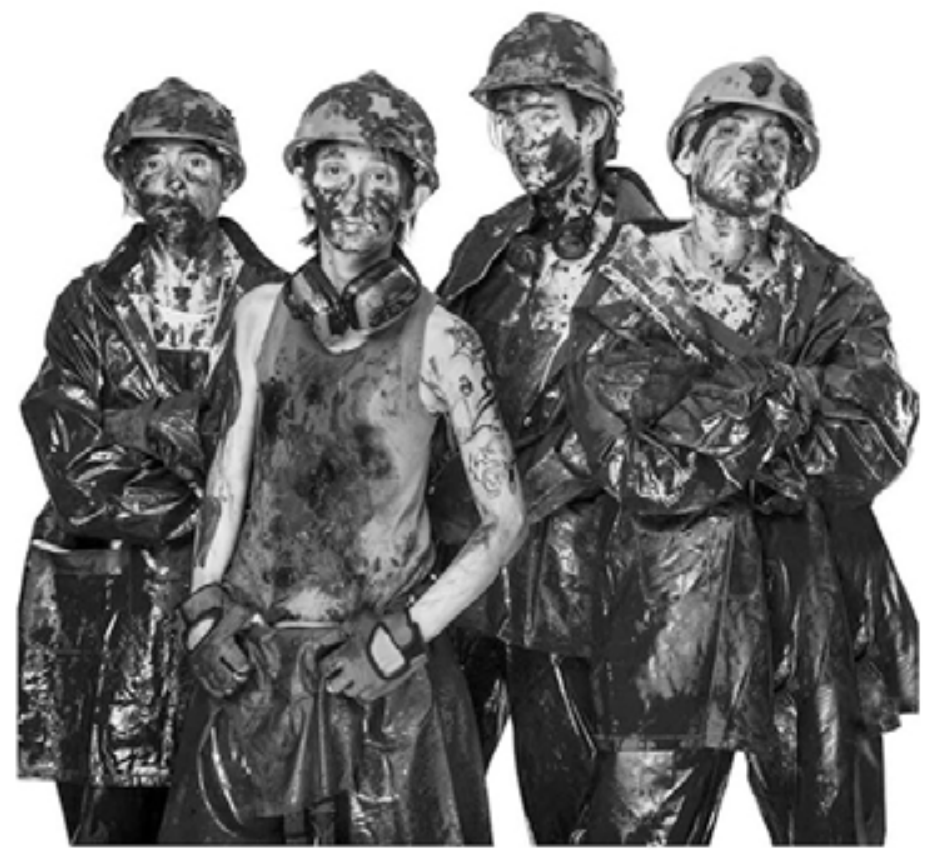

Imagen de promoción que fue parte del afiche de Petróleo

Fotografía de Carlos Furman 
A pesar de que no serían parte de las prácticas drag king los personajes que compuso el grupo Piel de lava, resulta de gran interés la indagación que realizaron en torno a la construcción de una masculinidad femenina. En la obra, uno de los principales procedimientos es el travestismo escénico. En términos de Trastoy y Zayas de Lima (2006) este sería un travestismo estetizante, es decir, «al ocultar o disimular sutilmente las marcas sexuales diferenciadoras, la transformación busca (...) despertar admiración ante el virtuosismo interpretativo» (pág. 99). La masculinidad que se pone en escena no es paródica. Las masculinidades representadas intentan ser humanizadas y realistas durante la obra (esta situación sufrirá un quiebre hacia el final de la obra). Este trabajo de composición se apoya en el vello facial que utilizan las actrices para formar barbas y bigotes, en el vestuario holgado que simula la ropa de trabajo de los personajes varones, en las voces levemente más graves, en los modos de comportarse y de habitar los espacios: las piernas expandidas, los modos de pararse con las piernas más abiertas, las tocadas a sus genitales cuando conversan. Incluso se perciben en los modos de socialización entre sí: los golpes, las pulseadas para medirse la fuerza que poseen, el hablar de las mujeres para reforzar su masculinidad heterosexual. Asimismo, se utilizan modos de expresión oral y de comunicación que socialmente son vinculados con las masculinidades.

Las fracturas de sus masculinidades comienzan con la llegada del cuarto personaje: el nuevo trabajador irá sacando de su bolso y poniéndose diferentes prendas que le ha comprado a su pareja mujer. Es así que se lo verá con un sweater con un gran felino cosido, con un tapado de piel marrón y terminará la obra luciendo unas medias largas de lycra que llevaba debajo de su pantalón y su pelo lacio y largo suelto. Al comienzo, resulta motivo de burla entre los personajes este uso de prendas asociadas como femeninas, pero con el correr de la obra, los mismos trabajadores varones se irán permitiendo explorar la feminidad. Al finalizar la obra, uno de ellos luce sus calzoncillos holgados con una remera de mangas cortas y tacos. Otro usará un vestido de lentejuelas con su pantalón holgado asomando por abajo.

De esta manera, se genera otro nivel de travestismo y de cuestionamiento. Al de las mujeres actrices que se visten como varones, se sumaría el de los personajes varones, al interior de la diégesis teatral, que se visten como mujeres. Incluso el personaje de Pilar Gamboa termina 


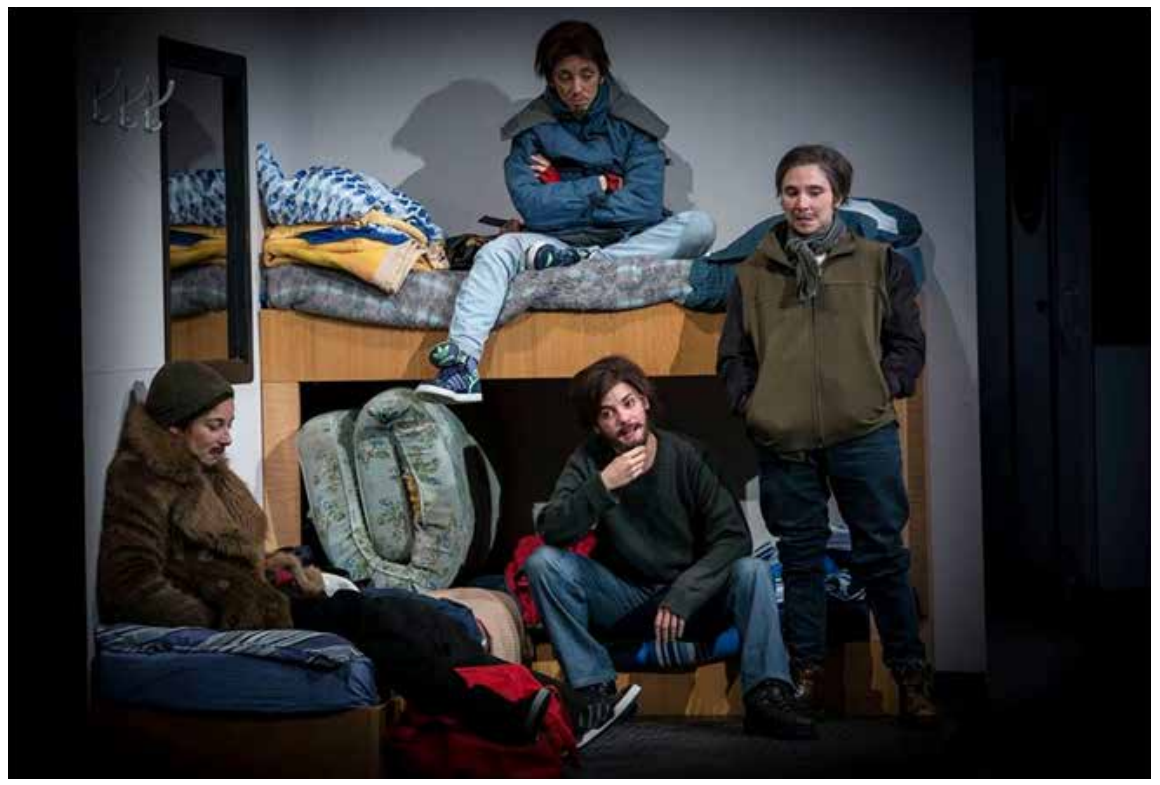

Escena de Petróleo en 2019. Fotografía de Carlos Furman

sacándose de su entrepierna el pene y depositándolo de manera lúdica sobre la mesa del tráiler. La exploración de estos varones parece culminar con este gesto de autocastración que no implica dolor; es la liberación del deseo de habitar de otro modo sus cuerpos y sus espacios de trabajo. Elijen tener energía eléctrica en el tráiler para sobrevivir al frío en lugar de alimentar la maquinaria que busca petróleo en el pozo y la pareciera ser que optan por la liberación de quitarse el peso de las normas sociales propias del patriarcado en torno a la masculinidad.

Por último, considero importante mencionar que también hubo, por parte de las actrices del grupo, diversas muestras de su posicionamiento político en su largo historial de funciones. En el momento del saludo final, se las vio con pañuelos de color verde apoyando la campaña nacional por la legalización del aborto como también mostraron carteles en apoyo al pueblo chileno durante las violentas represiones que este sufrió. En este punto nuevamente se vincula la manifestación artística con la política, como describí que sucedía en el espacio de Carrera de reyes. 


\section{AlgunOS ARRIBOS: ZONA EN CONSTRUCCIÓN}

Lo que encontramos a partir de los análisis realizados en este artículo es que, en lo que respecta a la investigación escénica en torno a las masculinidades femeninas, hay en principio dos estilos más marcados. Por un lado, en la escena drag king en Carrera de reyes, encontramos masculinidades que se constituyen con base en lo comunitario. Es decir, son espacios constituidos como lugares de identificación y de contención para quienes desean montarse. Las consignas de cada noche guían a quienes participan e invitan a pensar las masculinidades por fuera de los modos patriarcales y violentos. De esta manera tanto el trabajo que realizan Rey a Ruedas y Armando A. Bruno pone en primer plano la creatividad del vestuario y de la puesta en escena para llevar a cabo personajes que postulan consignas políticas vinculadas al transfeminismo. En una de las presentaciones, se puede leer en la espalda de Armando A. Bruno que «sin las travestis y las trans no hay feminismo». Con lo cual este lugar tiene una proyección política en quienes asisten a la vez que funciona como espacio de producción escénica y performática.

Por otro lado, en Petróleo encontramos que no hay, en principio, un trabajo drag, sino más bien un procedimiento de travestismo escénico. Aquí es nuevamente interesante el modo de construcción de la masculinidad dado que intenta situarse desde la complejidad de los trabajadores varones y las contradicciones que cargan como parte del sistema capitalista opresor. El sistema los oprime en términos laborales, pero también desde lo vincular y las actuaciones que deben llevar a cabo para reafirmar sus identidades. El modo en que las actrices exploran la masculinidad femenina no está puesto en lo caricaturesco o paródico, sino que se plantea desde un realismo. Hacia el final de la obra, este pacto realista se ve fracturado cuando los mismos personajes atraviesan un replanteamiento de sus modos de ser y habitar el mundo.

Pons Rabasa (2018) plantea que las prácticas Jrag king sacan a la luz «el proceso de materialización de los cuerpos mediante el cual no solamente devenimos sujetos, sino además sujetos de género, raza y clase social» (pág. 72). Esta postura desde lo interseccional, fue planteada tanto en las construcciones masculinas surgidas en la Carrera de reyes como en la obra de teatro Petróleo. Estos casos aquí trabajados son un intento por abordar, desde los estudios de género y desde la teatrología, las prácticas drag king que suelen ser aún menos abordadas que las 
manifestaciones artísticas de Jrag queens. Ambos ejercicios performativos son enriquecedores para complejizar y expandir las fronteras de lo teatral y de los modos en que se pueden llevar adelante las identidades.

El Jrag king como práctica resulta necesaria dado que explora la masculinidad que se erige a sí misma como el grado cero de la subjetividad, como el modo natural de habitar el mundo. Esta práctica demuestra, por un lado, que hay muchas masculinidades diversas por fuera de la masculinidad hegemónica que se presenta a sí misma como cisgénero, heterosexual, blanca y de clase media. Por otro lado, da cuenta de que es una construcción al igual que las demás identidades y que son plausibles de ser replanteadas y copiadas. No proponemos un voluntarismo identitario, como advierte Pons Rabasa, sino que buscamos señalar el potencial desestabilizador de estas prácticas y la posibilidad que nos brindan a les espectadores de entendernos como sujetos complejos que podemos replantearnos las categorías fijas que nos fueron impuestas.

\section{Obras citadas}

Bevacqua, Mina (2016). Hacia una cartografía teatral de las desobediencias sexuales. El Centro Cultural Rojas como epicentro de las deformances. Karpa 9 (2016-17): http://www.calstatela.edu/ al/karpa/mina-bevacqua

Butler, Judith (2000). Imitación e insubordinación de género. En Allouch et al., Grafías de Eros. Historia, género e identidades sexuales (págs. 87-114). Ciudad Autónoma de Buenos Aires: Edelp.

Dubatti, Jorge (2010). Filosofía del teatro II. Ciudad Autónoma de Buenos Aires: Atuel.

Halberstam, Judith (2008). Masculinidad femenina. Madrid: Editorial EGALES.

Haraway, Donna (1995 [1991]). Ciencia, ciborgs y mujeres. La reivindicación de la naturaleza. Madrid: Ediciones Cátedra.

Lozano, Ezequiel (2015). Sexualidades disidentes en el teatro. Buenos Aires, años 60. Ciudad Autónoma de Buenos Aires: Editorial Biblos.

Newton, Esther (1972). Mother Camp: Female Impersonators in America. Chicago: The University of Chicago Press. 
Pons Rabasa, Alba (2018). Los talleres Drag King: una metodología feminista de investigación encarnada. En Investigación teatral. Revista de artes escénicas y performatividad. Vol. 9, Núm. 13. Págs. 55-79.

Radi, Blas (2019). Políticas del conocimiento. Hacia una epistemología trans*. En Mariano López Seoane (comp.), Los mil pequeños sexos. Intervenciones críticas sobre políticas de género y sexualidades (págs. 27-42). Buenos Aires: Editorial de la Universidad Nacional de Tres de Febrero.

Sosa Cordero, Osvaldo (1978). Historia de las vaerités en Buenos Aires 19001925. Ciudad Autónoma de Buenos Aires: Ediciones Corregidor.

Trastoy, Beatrriz y Zayas de Lima, Perla (2006). Lenguajes escénicos. Ciudad Autónoma de Buenos Aires: Prometeo Libros.

Yaccar, María Daniela. Para nosotras el grupo es una posición política. En Página 12. 14 de febrero de 2019: https:/www.pagina12. com.ar/174864-para-nosotras-el-grupo-es-una-posicion-poli$\underline{\text { tica }}$

\section{Notas}

1 A lo largo del artículo, se utiliza el lenguaje inclusivo en búsqueda de un modo de comunicación que no sea sexista y que permita dar cuenta de la variedad de identidades de género que habitan el mundo. Esta idea se ve reforzada por la complejidad identitaria de quienes realizan las prácticas artísticas que aquí se trabajan y de quienes asistimos a eso espacios de celebración. Esta complejidad resulta en un reconocimiento a la pluralidad y a las disidencias que desde los comienzos de nuestra sociedad hemos estado presentes.

2 Queda para un trabajo próximo problematizar las ideas de «personaje drag» y de actuación para indagar sus pertinencias. Tal vez sería más conveniente, aunque más incómodo para su denominación, hablar de una identidad $\partial r a g$ y de momentos en que esta se comparte con espectadores. 